\title{
Drought-resistant fungi control soil organic matter decomposition and its response to temperature
}

\author{
J.C. YUSTE*, J. PEÑUELAS*, M. ESTIARTE*, J. GARCIA-MAS $\dagger, S . M A T T A N A *$, \\ R. OGAYA*, M. PUJOL† and J. SARDANS* \\ *Global Ecology Unit CREAF-CEAB-CSIC, CREAF (Centre de Recerca Ecológica i Aplicacions Forestals), Edifici C, Universitat \\ Autònoma de Barcelona, 08193 Bellaterra, Barcelona, Spain, †IRTA, Centre de Recerca en Agrigenòmica CSIC-IRTA-UAB, \\ Carretera de Cabrils Km 2, 08348 Cabrils, Barcelona, Spain
}

\begin{abstract}
Microbial-mediated decomposition of soil organic matter (SOM) ultimately makes a considerable contribution to soil respiration, which is typically the main source of $\mathrm{CO}_{2}$ arising from terrestrial ecosystems. Despite this central role in the decomposition of SOM, few studies have been conducted on how climate change may affect the soil microbial community and, furthermore, on how possible climate-change induced alterations in the ecology of microbial communities may affect soil $\mathrm{CO}_{2}$ emissions. Here we present the results of a seasonal study on soil microbial community structure, SOM decomposition and its temperature sensitivity in two representative Mediterranean ecosystems where precipitation/throughfall exclusion has taken place during the last 10 years. Bacterial and fungal diversity was estimated using the terminal restriction fragment length polymorphism technique. Our results show that fungal diversity was less sensitive to seasonal changes in moisture, temperature and plant activity than bacterial diversity. On the other hand, fungal communities showed the ability to dynamically adapt throughout the seasons. Fungi also coped better with the 10 years of precipitation/throughfall exclusion compared with bacteria. The high resistance of fungal diversity to changes with respect to bacteria may open the controversy as to whether future 'drier conditions' for Mediterranean regions might favor fungal dominated microbial communities. Finally, our results indicate that the fungal community exerted a strong influence over the temporal and spatial variability of SOM decomposition and its sensitivity to temperature. The results, therefore, highlight the important role of fungi in the decomposition of terrestrial SOM, especially under the harsh environmental conditions of Mediterranean ecosystems, for which models predict even drier conditions in the future.
\end{abstract}

Keywords: bacteria, climate change, diversity, drought, fungi, $Q_{10}$, soil organic matter decomposition

Received 4 February 2010; revised version received 16 July 2010 and accepted 19 July 2010

\section{Introduction}

Soil organic matter (SOM) decomposition, involving oxidation of SOM by heterotrophs and transport of the resulting $\mathrm{CO}_{2}$ through the soil, ultimately contributes very significantly to soil $\mathrm{CO}_{2}$ efflux (BondLamberty et al., 2004), and thus to global $\mathrm{CO}_{2}$ emissions. How climate change will perturb SOM decomposition and hence the soil organic carbon $(C)$ reservoir remains, however, controversial (Kirschbaum, 2006). While current models predict that global warming will increase the net $\mathrm{CO}_{2}$ emissions from terrestrial ecosystems due to the strong sensitivity of heterotrophic respiration to temperature (Cox et al., 2000; Friedlingstein et al., 2003), other studies also highlight the large uncertainties associated to predicting the soil emissions component (Meir et al., 2006). These uncertainties are primarily due

Correspondence: J. C. Yuste, tel. + 3493581 4677, fax + 3493581 4151, e-mail: j.curiel@creaf.uab.es to the limited knowledge about the mechanisms underlying soil respiration (Davidson \& Janssens, 2006).

Among the questions that remain unresolved, the role of microbial diversity in SOM decomposition could be of paramount importance. Although the microbial community responsible for decomposing SOM is rarely considered explicitly in models (Moorhead \& Sinsabaugh, 2006; Allison \& Martiny, 2008) the structure and functioning of soil microbial communities is affected by seasonality and site characteristics (Lipson et al., 2002, 2009; Waldrop \& Firestone, 2006a, b; Schmidt et al., 2007; Williams, 2007; Williams \& Rice, 2007). Moreover, although some evidence suggests that the complexity (functional or specific) of the soil microbial community may positively affect SOM decomposition (Deacon, 1985; Robinson, 1993; Wall, 1999; Hulot, 2000; Aerts, 2006; Strickland et al., 2009) or the activity of the microflora (Degens, 1998; Griffiths et al., 2000), the relation between the diversity and the system function remains in question (Deacon, 1985; Rayner, 1994; Cox, 2001). 
Another source of controversy is deciphering the relative contribution of the different microbial functional groups such as fungi and bacteria to SOM decomposition and these groups' direct effect on C terrestrial C cycling (e.g. Bardgett et al., 1996). In terrestrial ecosystems, where soil pores are filled with air and SOM is highly protected (physically, chemically or biochemically), fungi have an adaptive advantage with respect to bacteria, which have dominated aquatic ecosystems (De Boer et al., 2005). The inability of the bacterial unicellular body form to bridge these air-filled voids has been overcome by the hyphal/mycelial growth form, especially present in fungi (Griffin, 1985), which facilitates organisms to cross water-poor and/or nutrient-poor spots in soil in searching for the heterogeneously distributed water/nutrient resources (Jennings, 1987). Although actinomycetes, have also developed the hyphal growth form (Griffin, 1985), this has not enabled bacteria to monopolize terrestrial heterotrophic processes. A shift to a fungal world could have consequences for $\mathrm{C}$ cycling for different reasons: firstly, because fungal decomposers have developed pathways to degrade recalcitrant structural compounds unique to terrestrial vascular plants (e.g. lignin) and these pathways are not present in bacteria (Ewbank et al., 1996; Robinson, 1996; Taylor \& Osborne, 1996), and secondly, because various studies have suggested that bacteria and fungi cycle $C$ very distinctly due to different growth efficiencies (Holland \& Coleman, 1987), a different quality of by-products generated by their activity (Martin \& Haider, 1979) and/or a different involvement in the physical stabilization of organic matter (Six et al., 2006).

Mediterranean ecosystems are an exceptional playground to test how microbial communities would evolve under more arid conditions. In Mediterraneantype ecosystems water availability is already the most important environmental constraint, due to the combination of high summer temperatures and low rainfall (Specht et al., 1983; Larcher, 2000). This region is therefore expected to be extremely vulnerable to the effects of climate change (Schröter et al., 2005). Drought limits the physiological performance of microbes and the diffusion of nutrients in the soil pore space (Harris, 1981; Papendick \& Campbell, 1981; Robinson et al., 1993). It therefore submits the microbial community to an important adaptive force. Furthermore, current global circulation and regional models predict an increase in temperatures in the Mediterranean Basin during the present century, while rainfall is predicted to decrease and become more irregular (Gibelin \& Deque, 2003; IPCC, 2007). Given that soil microbial communities exhibit seasonal changes, the impact of increasing drought levels is likely to depend on changes in rainfall seasonality, especially if rainfall decreases at times when there normally is some rainfall. It is therefore important to assess whether the ongoing global changes in climate and the subsequent effects on soil moisture, vegetation and soil chemical and biochemical properties may affect the distinct role of fungi and bacteria.

Here we present the results of a study designed to explore the role of certain ecological aspects of the soil microbial community (e.g. biomass and diversity) in the variability of SOM decomposition. Ecological attributes of the microbial community such as microbial biomass, fungal biomass, bacterial and fungal diversity as well as other soil biogeochemical attributes [total organic carbon (TOC)] were studied seasonally at two Mediterranean sites where precipitation exclusion has been taking place during the last 10 years, reducing soil moisture up to $20 \%$ with respect to controls (Ogaya \& Peñuelas, 2007; Peñuelas et al., 2007). These results were compared with parallel measurements of SOM decomposition and its response to temperature. Our hypotheses were (1) site and seasonality exert a strong influence over the microbial community structure and its diversity; (2) drought simulations will affect the drought-sensitive bacterial community more than the drought-tolerant fungal community and (3) the drought-tolerant fungal community exerts a strong influence over the temporal and spatial variability of SOM decomposition and its response to temperature changes.

\section{Materials and methods}

\section{Experimental sites}

Soil samples were collected from two different experimental sites, a holm-oak forest (Prades) and a schrubland (Garraf), where precipitation/throughfall exclusion has been maintained over the last 10 years.

The natural holm-oak (Quercus ilex) forest of the Prades Mountains is located in Southern Catalonia (North-Eastern Iberian Peninsula) (418130N, 08550E), on a south-facing slope (25\%). The soil is a stony Dystric Xerochrept (Soil Survey Staff, 1998) on a bedrock of metamorphic sandstone. Its depth ranges between 35 and $100 \mathrm{~cm}$. Depth of Horizon A ranges between 25 and $30 \mathrm{~cm}$. The average annual temperature is $12.8^{\circ} \mathrm{C}$ and the average annual rainfall is $658 \mathrm{~mm}$. Summer drought is pronounced and usually lasts for 3 months. The vegetation is a dense forest dominated by $Q$. ilex $L$. as a dominant tree with abundant presence of Phillyrea latifolia and Arbutus unedo L. and other evergreen species well adapted to drought conditions (Erica arborea L., Junniperus oxycedrus L. and Cistus albidus L.), and occasional individuals of deciduous species (Sorbus torminalis L. Crantz and Acer monspessulanum L.). Eight $15 \mathrm{~m} \times 10 \mathrm{~m}$ plots were established at the same altitude (930 $\mathrm{m}$ above sea level) along the slope in 1999. Four of the plots received the drought treatment and the other half 
were control plots. The drought treatment consisted of partial throughfall exclusion by suspending PVC strips and funnels at a height of $0.5-0.8 \mathrm{~m}$ above the soil surface. Strips and funnels covered approximately $30 \%$ of the total plot surface. Two plastic strips of $14 \mathrm{~m}$ long and $1 \mathrm{~m}$ wide were placed along the drought treatment plots from the top until the bottom part, and 30 plastic funnels of $1 \mathrm{~m}^{2}$ each one were randomly placed in each drought treatment plot. A $0.8-1 \mathrm{~m}$ deep ditch was excavated along the entire top edge of the upper part of the treatment plots to intercept runoff water supply. The water intercepted by strips, funnels and ditches was conducted outside the plots, below their bottom edge. Within the drought treatment we further distinguished two treatments: mild drought, corresponding to soils of the drought treatment only affected by the intercept runoff (trenching) and severe drought, which corresponded to soils affected by both, water runoff (trenching) and throughfall exclusion (plastics strips). Therefore, the study area consisted of three treatments (control, mild drought and severe drought) with four replicates per treatment.

The Mediterranean calcareous shrubland on a south-facing slope in the Garraf Mountains is also located in southern Catalonia (NE Spain) $(418180 \mathrm{~N}, 18490 \mathrm{E})$ at $210 \mathrm{~m}$ above sea level. The site is located on formerly cultivated terraces abandoned approximately a century ago - with a Petrocalcic calcixerepts (Soil Survey Staff, 1998) soil lying on bedrock of sedimentary limestone. The average annual temperature is $15.1^{\circ} \mathrm{C}$ and the average annual rainfall was $580 \mathrm{~mm}$ (Period 1999-2004). The summer drought is pronounced and usually lasts for 3 months. The total vegetation cover is $70 \%$ and consists of a calcareous shrubland with plants about $1 \mathrm{~m}$ high, dominated by the shrubs Globularia alypum, Erica multiflora, Dorycnium pentaphyllum, Rosmarinus officinalis, Ulex parviflorus and Pistacia lentiscus. Field-scale drought, warming and control treatments were applied in three plots/replicates per treatment. The warming treatment consisted in increasing nighttime temperatures by covering the vegetation with an aluminum curtain coiled on a beam and connected to a motor controlled by light sensors that automatically covered the vegetation at night. This curtain reflected long-wave infrared radiation back into the vegetation, resulting in a temperature increase in relation to untreated plots. In order to avoid interfering with the hydrological cycle, roofs were automatically removed when it rained. The drought treatment reduced spring and autumn rainfall input. This was achieved by automatically covering vegetation with a transparent plastic curtain during periods of rain by means of automatic rain sensors. Once the rain stopped, the curtain was automatically removed. Roofs were removed if wind speed exceeded $1 \mathrm{~m} \mathrm{~s}^{-1}$. Given that plots were located on a slope, pipes were laid along the upper edges of the drought plots to minimize runoff water entering. The control plots were equipped with the same scaffolding as the treatment plots, without the roof. Each plot occupied an area of $4 \mathrm{~m} \times 5 \mathrm{~m}$, and to avoid the effect of edge disturbance, samples were only taken from an internal area of 3-4 m. Manipulation started in March 1999 and has continued up to the present day.

For more information about the experimental sites and drought treatments see Peñuelas et al. (2007) and Ogaya \& Peñuelas (2007).

\section{SOM decomposition and temperature sensitivity}

Soil cores, $4.5 \mathrm{~cm}$ diameter and $10 \mathrm{~cm}$ depth, were collected using a stainless steel core soil sampler. Samples were collected during three different periods of the year, winter (cold and moist with little vegetation activity), spring (warm and wet with maximum vegetation activity) and summer (very warm and very dry, with minimum vegetation activity).

In Prades, three samples were collected per replicate (four replicates) for each treatment (control, mild drought and severe drought) and period (winter, spring and summer). In total 36 samples per period, 12 for control, 12 for mild drought (trenched but not covered by PVC strips) and 12 for severe drought (trenched and covered by PVC strips). A total number of 108 soil samples were collected in Prades for this experiment. In Garraf, three samples were collected per replicate (three replicates) for each treatment (ctrl, drought and warming) and period (winter, spring and summer). In total 27 samples per period, nine for control, nine for drought and nine for warming and a total number of 81 soil samples were collected in Garraf.

Soils samples were sieved $(2 \mathrm{~mm})$ and stored in plastic jars. To assess the temperature sensitivity of soil decomposition, soils were subjected to temperature cycles following a similar procedure to that followed by Yuste et al. (2007) and Yuste et al. (2010). Before the temperature cycles, sieved soils were maintained at room temperature (approximately $23^{\circ} \mathrm{C}$ ) 3 days. Soil moisture was kept as it was at soil collection by maintaining the plastic jars closed during the whole process, avoiding evaporation. During each cycle respiration rates were measured at three temperatures: 10,25 and $45^{\circ} \mathrm{C}$. These temperatures are experienced at the site from winter to summer. Incubation temperature was not gradually increased and soil cores went straight from one temperature to the other. Soil $\mathrm{CO}_{2}$ efflux from the soil samples was measured at each of the three temperatures $24 \mathrm{~h}$ after the given temperature was applied. Thirty minutes before measurement jars were opened to equilibrate the air $\mathrm{CO}_{2}$ concentrations of the jar and the room. After the $30 \mathrm{~min}$ we used a modified soil chamber connected to an EGM-4 portable system (PP-systems, Hitchin, UK) to measure soil $\mathrm{CO}_{2}$ efflux. Commercial soil chamber of PP-systems, the SRC-1, was enlarged with a $1 \mathrm{~L}, 13 \mathrm{~cm}$ large PVC tube of the same diameter as the SRC- 1 chamber and with a rubber rim at the end. Plastic jars containing the incubated soils were then introduced into the enlarged chamber, sealing the inner volume as a closed system. The modified chamber produced readings similar to those obtained with the commercial SRC-1.

In addition we used the decomposition rates obtained at each of the incubation temperatures to assess the relative increase in soil decomposition with temperature. $Q_{10}$ computes the relative increase in decomposition rate per $10^{\circ} \mathrm{C}$ difference.

$$
F_{\mathrm{a}}=F_{\mathrm{a} 10} Q_{10}^{T-10 / 10},
$$

where $F_{\mathrm{a}}$ is the measured soil $\mathrm{CO}_{2}$ efflux, $F_{\mathrm{a} 10}$ is the basal respiration rate at $10^{\circ} \mathrm{C}, Q_{10}$ is the relative change in $F_{\mathrm{a}}$ with $10^{\circ} \mathrm{C}$ increases and $T$ is the temperature of soil at measurement time. We fitted this exponential function for each of the four soils studied.

We used the soil $\mathrm{CO}_{2}$ efflux averaged over all the temperatures as the rate of SOM decomposition per site and treatment. 


\section{Microbial biomass and TOC}

Microbial biomass in the sample was measured by the chloroform-fumigation-extraction method (Vance et al., 1987) after incubation for 4 days in the dark at $25^{\circ} \mathrm{C}$ to eliminate the effects of sampling, sieving and storage. Unfortunately, analyses of microbial biomass were only performed on soils collected in the winter and spring. TOC was measured by oxidation with potassium dichromate and the assessment of excess chromic acid not consumed by an iron salt (salt Mhor).

\section{Fungal biomass}

Fungal biomass was estimated using the ergosterol method (Grant \& West, 1986). For the measurement $2 \mathrm{~g}$ (wet weight) of freeze dried soil was extracted with $16 \mathrm{~mL}$ methanol, vortexed and then submitted to an ultrasonic bath for $30 \mathrm{~min}$ and centrifuged for $10 \mathrm{~min}$ at $1600 \mathrm{~g}$. The ergosterol material extracted was analyzed by HPLC (WATERS 2965 Separations Module, Milford, MA, USA) with a PDA detector (WATERS 2996). Ergosterol was confirmed by comparing retention times and absorption spectrum with an external standard (Fluka, Buchs, Switzerland) and by coinjection of samples plus standard ergosterol. Thus,

$$
\mathrm{g}^{\text {Ergosterol }^{-1}} \text { soil }(\mathrm{DM})=\mathrm{A} \times \mathrm{S} \times 2 / R \times \mathrm{DM},
$$

where $A$ is the peak area of ergosterol in the sample; $S$ is the slope of the standard curve ( $\mu$ g ergosterol per unit of peak area); 2 is the sample volume; DM is dry matter content of the soil sample analyzed and $R$ is the added standard recovery.

\section{DNA extraction}

Soil DNA was extracted from Prades soil samples using the PowerSoil $^{\mathrm{TM}}$ DNA Isolation Kit (MoBio Laboratories Inc., Carlsbad, CA, USA) as recommended by the manufacturer. The MoBio ultraclean DNA soil kit (MoBio Laboratories Inc.) was used to extract DNA from Garraf soil. The PowerSoil Isolation Kit differs from the MOBIO UltraClean Soil DNA isolation kit (Solana Beach, CA, USA) because of a different humic substance removal procedure. Briefly, the DNA extraction methods involved chemical lysis of microbial cells with gentle bead-beating, released DNA was bound to a silica spin filter which was subsequently washed, and the DNA was recovered in elution buffer solution. DNA yields and quality were checked after electrophoresis in $0.8 \%(\mathrm{w} / \mathrm{v})$ agarose gel stained with ethidium bromide under UV light (Sambrook et al., 1989).

\section{Bacterial and fungal community fingerprinting by terminal restriction fragment length polymorphism (TRFLP) analysis}

The 16S rRNA from the extracted DNA samples was amplified using the universal eubacterial primers $8 \mathrm{~F}$, a fluorescently labelled forward primer (AGAGTTTGATCCTGGCTCAG) and primer 1398R (ACGGGCGGTGTGTACAAG). Fungal DNA was amplified using the highly conserved fungal rRNA gene primers ITS1-F (CTTGGTCATTTAGAGGAAGTAA) and
ITSF4 (TCCTCCGCTTATTGATATGC). The forward primer ITS 1-F was labelled with fluorescent dye 6 FAM (Applied BioSystem, Warrington, UK). PCR reactions were performed in $25 \mu \mathrm{L}$ PCR Master Mix by Promega (Madison, WI, USA) (containing 50 units $\mathrm{mL}^{-1}$ Taq DNA polymerase in a proprietary reaction buffer, $400 \mu \mathrm{L}$ each dNTP and $3 \mathrm{mM} \mathrm{MgCl}_{2}$ ) $10 \mu \mathrm{M}$ of each primer and $1 \mu \mathrm{L}$ of template DNA.

The thermocycling conditions for bacterial DNA were as follows, a hot start at $95^{\circ} \mathrm{C}$ for $3 \mathrm{~min}$ (one cycle); $95^{\circ} \mathrm{C}$ for $30 \mathrm{~s}$, $53^{\circ} \mathrm{C}$ for $30 \mathrm{~s}, 7{ }^{\circ} \mathrm{C}$ for $1 \mathrm{~min}$ ( 35 cycles); with a final extension at $72{ }^{\circ} \mathrm{C}$ for $7 \mathrm{~min}$. The thermocycling conditions for fungal DNA were as follows, a hot start at $94^{\circ} \mathrm{C}$ for $4 \mathrm{~min}$ (one cycle); $94{ }^{\circ} \mathrm{C}$ for $1 \mathrm{~min}, 55^{\circ} \mathrm{C}$ for $1 \mathrm{~min}, 72^{\circ} \mathrm{C}$ for $2 \mathrm{~min}$ ( 40 cycles); with a final extension at $72{ }^{\circ} \mathrm{C}$ for $7 \mathrm{~min}$.

PCR products of the correct size were confirmed by $1 \%$ $(\mathrm{w} / \mathrm{v})$ agarose gel electrophoresis and subsequently purified using UltraClean ${ }^{\circledR}$ PCR Clean-Up Kit (MoBio Laboratories Inc.) according to manufacturer's instructions $(50 \mu \mathrm{L}$ final volume). The purified PCR product $(30 \mu \mathrm{L})$ was then digested with $2 \mathrm{U}$ of $\mathrm{Ms} p \mathrm{I}$ restriction enzyme (Biolabs) in the manufacturer's buffer (total reaction volume $50 \mu \mathrm{L}$ ) overnight at $37^{\circ} \mathrm{C}$. Samples were analyzed using an automated sequencer $\mathrm{ABI}$ Prism 3100 Genetic Analyzer (Applied Biosystems).

TRFLP profiles were produced using the GeneMapper software (version 3.7; ABI, United Kingdom). Terminal restriction fragments (TRFs) were quantified using the advanced mode and second-order algorithm. Only peaks at positions between 50 and $700 \mathrm{bp}$ were considered. The relative abundance of a TRF in a TRFLP profile was calculated by dividing the peak height of the TRF by the total peak height of all TRFs in the profile. All peaks with heights that were $<0.5 \%$ of the total peak height were not included in further analyses. This approach minimized the effect of variations in the TRFLP profiles caused by the quantity of DNA analyzed. TRF profiles were aligned to prevent incorrectly identifying one TRF peak as two separate peaks. The TRF peaks that differed by $<0.5 \mathrm{bp}$ were then considered identical, and were clustered together.

\section{Statistical methods}

The effects of season and treatment on bacterial and fungal community structure were assessed using data on both TRF fragment proportional area and in presence/absence of TRF's. Principal component analyses (PCA) were conducted to reduce the $n$-dimensional data of TRF's obtained for each sample into a series of linear axes that explain the maximum amount of variance in the data. The relative position of each sample along the principal-component axes can then be used to describe the degree of community-level similarity between samples.

Additionally, number and area of TRF peaks was used to describe the diversity of TRF's in the samples. Soil TRF richness was calculated as the total number of distinct TRF sizes (between 50 and $700 \mathrm{bp}$ ) in a profile. The ShannonWeaver diversity index was calculated as follows:

$$
\text { Shannon-Weaver }(H)=\frac{C}{N}\left(N \times \log _{10} N-\sum n_{i} \log _{10} n_{i}\right) \text {, }
$$


where $\mathrm{C}$ is 2.3, $N$ the sum of peak areas in a given TRFLP profile, $n_{\mathrm{i}}$ the area of TRF $i$ and $i$ the number of TRFs in each TRFLP profile.

We used repeated measures analysis of variance (ANOVA) to study the effect of site, season and treatment over the variables and indexes generated. For treatment we only tested the effect of drought treatment (Garraf) and severe drought (Prades) because previous analyses suggested only a slight effect of warming (Garraf) and mild drought (Prades) on the variables studied (data not shown). We, therefore, removed the 'warming' treatment of Garraf and the 'mild drought' treatment of Prades from this analysis. We also applied a repeated measure ANOVA to investigate the effect of site, season and treatment on factors 1 and 2 generated by the PCA.

The correlation of different environmental variables with SOM decomposition and its sensitivity to temperature was studied by averaging the data per treatment and season. We averaged the value of the three samples collected per plot (replicates) before analysis. Additionally, statistics were performed on the average of the three replicates in Garraf and the four replicates in Prades. Therefore statistics were performed on nine means per site corresponding to three treatments and three seasons. We performed two different correlation tests (1) Pearson's correlations to investigate the correlation of each environmental variable with SOM decomposition and $Q_{10}$; and (2) stepwise multiple regressions were additionally applied to study the relative contribution of environmental variables to the variability of SOM decomposition and $Q_{10}$. We reduced the number of explicative variables to five to reduce redundancy. The criteria to choose those five environmental variables were that they generated high Pearson's correlation coefficients and that they were representative of different environmental factors, e.g. climate (moisture), soil biogeochemistry (soil organic C), microbial biomass (fungal biomass) and microbial diversity (fungal and bacterial TRF richness).

All analyses were conducted using STATISTICA 6.0 (StatSoft Inc., OK, USA).

\section{Results}

Values for microbial and fungal biomass, as well as diversity indexes for bacteria and fungi derived from the analyses of TRF profiles are reported in Table 1. Results from the repeated measures ANOVA showed considerable effects of site, season and treatment over the structure of the soil microbial community (Table 2). In general, the holm-oak forest site showed values for biomass (microbial and fungal) and fungal diversity significantly higher than those found in the Mediterranean shrubland (Table 2). Bacterial diversity, on the other hand, did not differ significantly between sites (Table 2). Fungal and bacterial community structure was also strongly influenced by site, as illustrated by the ordination plots of the first and second axis of the PCA analyses (Fig. 1, Table 2). Within-sites, season strongly affected fungal biomass, which peaked during winter at both sites (Table 1) especially in Prades. Treatment did not affect significantly microbial and/ or fungal biomass (Table 2) although at both sites microbial biomass was proportionally more affected than fungal biomass alone (Table 1).

The study of the diversity indexes (richness and/or Shannon-Weaver diversity index) further revealed that bacterial diversity was, in general, more affected by season and drought than fungal diversity (Table 2). Season affected bacterial diversity especially in Garraf, where both diversity indexes (richness and ShannonWeaver) showed strong sensitivity to seasonality (Table 2). In this Mediterranean shrubland, the lowest bacterial diversity values were obtained during winter, when soils have the lowest temperatures. In Prades, on the other hand, the lowest bacterial diversity values were obtained under the driest summer conditions (Table 1), but only the Shannon-Weaver diversity index showed some sensitivity to seasonality (Table 2). The 10 years precipitation exclusion exerted, in general, a stronger effect over bacterial diversity than did seasonality (Table 2). While in Prades (holm-oak forest) drought affected equally bacterial diversity at all seasons (Table 1), at Garraf the main effect was observed in spring, when bacterial diversity was significantly higher in the control with respect to the precipitation exclusion plots (Table 1; see effect of season $\times$ treatment in Table 2). Neither seasonality nor treatment affected fungal diversity significantly at any of the sites (Table 2).

Results of the PCAs indicate that season strongly influenced the structure of the microbial community, but treatment did not (Fig. 1, Table 2). The effect of seasonality was strong in the Mediterranean shrubland (Garraf) where ordinates generated by the first and second dimensions clearly separated both bacterial and fungal communities by season rather than treatment (Fig. 1a and b). Treatment only exerted a significant effect in the microbial community structure of spring soils (Fig. 1, Table 2), when plant activity was typically maximal at this Mediterranean site (Peñuelas et al., 2007). Although season influenced significantly the microbial community structure at both experimental sites, the effect on both the fungal and bacterial community structure appeared to be, in general, stronger in Garraf than in Prades (Fig. 1).

We wanted to further test how microbial community structure may affect SOM decomposition and its sensitivity to temperature. Variability of soil $\mathrm{CO}_{2}$ effluxes (SOM decomposition) measured under laboratory conditions was best explained by variations in soil fungal biomass, both within and between ecosystems (Fig. 2a, see Table 3). Values of fungal biomass and values of SOM decomposition were both generally 
Table 1 Measured variables averaged per treatment/season

\begin{tabular}{cllllllllllllllllllll}
\hline Site & Season & Treat & SWC & SE & $R_{\mathrm{h}}$ & $\mathrm{SE}$ & $Q_{10}$ & $\mathrm{SE}$ & $\mathrm{MB}$ & $\mathrm{SE}$ & $\mathrm{FB}$ & $\mathrm{SE}$ & $\mathrm{BR}$ & $\mathrm{SE}$ & $\mathrm{BH}$ & $\mathrm{SE}$ & $\mathrm{FR}$ & $\mathrm{SE}$ & $\mathrm{F} H$ & $\mathrm{SE}$ \\
\hline Winter & Control & 0.15 & 0.02 & 0.7 & 0.1 & 2.7 & 0.3 & 529 & 71 & 4.9 & 0.3 & 7.7 & 0.9 & 1.9 & 0.1 & 21 & 3.2 & 1.6 & 0.2 \\
Spring & Control & 0.19 & 0.01 & 0.4 & 0.1 & 0.9 & 0.0 & 308 & 71 & 3.6 & 2.4 & 28.7 & 6.2 & 3.1 & 0.2 & 14.3 & 8.9 & 1.4 & 0.6 \\
Summer & Control & 0.07 & 0 & 0.3 & 0.1 & 1.7 & 0.1 & & & 2.0 & 0.3 & 22.3 & 3.8 & 2.8 & 0.2 & 26.5 & 6.4 & 2.2 & 0.4 \\
Garraf & & & & & & & & & & & & & & & & & & & \\
Winter & Drought & 0.16 & 0.01 & 0.4 & 0.0 & 2.5 & 0.3 & 451 & 67 & 3.8 & 0.9 & 7 & 1 & 1.8 & 0.1 & 26.7 & 8 & 1.9 & 0.5 \\
Spring & Drought & 0.17 & 0.02 & 0.6 & 0.2 & 1.2 & 0.1 & 266 & 53 & 2.9 & 0.8 & 5.3 & 2 & 1.4 & 0.3 & 20.3 & 3.6 & 1.5 & 0.2 \\
Summer & Drought & 0.06 & 0.01 & 0.3 & 0.1 & 1.9 & 0.2 & & & 1.8 & 0.2 & 21.6 & 5.1 & 2.6 & 0.3 & 12.6 & 3.8 & 1.4 & 0.2 \\
Winter & Control & 0.16 & 0 & 4.5 & 1.2 & 4.7 & 0.6 & 737 & 273 & 13.4 & 1.8 & 25.3 & 6.2 & 2.7 & 0.2 & 53.1 & 6.2 & 2.7 & 0.2 \\
Spring & Control & 0.2 & 0.02 & 0.9 & 0.4 & 1.9 & 0.3 & 843 & 169 & 4.8 & 1.2 & 25.6 & 10.2 & 2.4 & 0.3 & 45.9 & 4.3 & 2.7 & 0.1 \\
Summer & Control & 0.09 & 0.01 & 1.2 & 0.5 & 8.8 & 1.2 & & & 1.8 & 0.5 & 13.5 & 3.1 & 2.3 & 0.3 & 71 & 5.5 & 3.2 & 0.1 \\
Prades & & & & & & & & & & & & & & & & & & \\
Winter & Drought & 0.1 & 0 & 2.5 & 1.1 & 3.8 & 0.4 & 673 & 224 & 10.2 & 1.2 & 14.6 & 4 & 2.3 & 0.2 & 50.1 & 5.7 & 2.7 & 0.1 \\
Spring & Drought & 0.18 & 0.01 & 0.9 & 0.3 & 2.5 & 1.4 & 578 & 250 & 7.1 & 2.3 & 8.9 & 2.5 & 1.8 & 0.3 & 48.1 & 6.4 & 2.6 & 0.2 \\
Summer & Drought & 0.05 & 0.01 & 0.2 & 0.1 & 4.3 & 0.8 & & & 2.4 & 0.7 & 6.1 & 1.5 & 1.5 & 0.2 & 52.4 & 7.8 & 2.6 & 0.2 \\
\hline
\end{tabular}

SWC: soil moisture, $\mathrm{g} \mathrm{H}_{2} \mathrm{Og}^{-1}$ dry soil; $\mathrm{Rh}$ : $\mathrm{SOM}$ decomposition; $\mathrm{mg} \mathrm{CO}_{2} \mathrm{~g}^{-1}$ soil h$^{-1}$; MB: microbial biomass; $\mu \mathrm{g} \mathrm{Cg}{ }^{-1}$ dry soil; FB: fungal biomass; $\mu \mathrm{g} \mathrm{erg} \mathrm{g}{ }^{-1}$ dry soil.

$\mathrm{BR}$, bacterial richness; $\mathrm{BH}$, bacterial Shannon-Weaver; FR, fungal richness; FH, fungal Shannon-Weaver; SE, standard error of the mean; SOM, soil organic matter.

Table $2 F$ coefficient and $P$ values of the repeated measures ANOVA

\begin{tabular}{|c|c|c|c|c|c|c|c|c|c|c|c|c|c|c|c|c|}
\hline & \multicolumn{2}{|l|}{ MB } & \multicolumn{2}{|l|}{$\mathrm{FB}$} & \multicolumn{2}{|l|}{ BR } & \multicolumn{2}{|l|}{$\mathrm{BH}$} & \multicolumn{2}{|l|}{ FR } & \multicolumn{2}{|l|}{$\mathrm{FH}$} & \multicolumn{2}{|l|}{ B PCA } & \multicolumn{2}{|c|}{ F PCA } \\
\hline & $F$ & $P$ & $F$ & $P$ & $F$ & $P$ & $F$ & $P$ & $F$ & $P$ & $F$ & $P$ & $F$ & $P$ & $F$ & $P$ \\
\hline \multicolumn{17}{|l|}{ All } \\
\hline Site & 7.317 & $0.009^{*}$ & 14.261 & $0.000^{* * *}$ & 0.016 & 0.900 & 1.076 & 0.303 & 71.367 & $0.000^{* * *}$ & 59.147 & $0.000^{* * *}$ & 51.194 & $0.000^{* * *}$ & 9.626 & $0.000^{* * *}$ \\
\hline Season & 0.616 & 0.436 & 16.986 & $0.000^{* * *}$ & 0.466 & 0.629 & 0.066 & 0.936 & 1.823 & 0.169 & 2.252 & 0.112 & 4.804 & $0.000^{* * *}$ & 5.936 & $0.000^{* * *}$ \\
\hline Treat & 0.340 & 0.562 & 0.451 & 0.504 & 10.850 & $0.002^{* *}$ & 20.672 & $0.000^{* * *}$ & 0.843 & 0.362 & 1.231 & 0.271 & 2.253 & 0.111 & 0.287 & 0.751 \\
\hline \multicolumn{17}{|l|}{ Garraf } \\
\hline Season & 7.637 & $0.011^{*}$ & 6.703 & $0.004^{* *}$ & 8.438 & $0.001^{* *}$ & 5.900 & $0.007^{*}$ & 0.196 & 0.823 & 1.184 & 0.322 & 6.345 & $0.004^{* *}$ & 6.033 & $0.000^{* * *}$ \\
\hline Treat & 0.022 & 0.883 & 0.000 & 0.994 & 10.437 & $0.003^{* *}$ & 16.085 & $0.000^{* * *}$ & 0.070 & 0.793 & 0.011 & 0.917 & 0.876 & 0.355 & 0.637 & 0.534 \\
\hline$S \times T$ & 0.117 & 0.736 & 0.040 & 0.961 & 5.301 & $0.0114^{* *}$ & 5.651 & $0.009 * *$ & 2.832 & 0.076 & 2.900 & 0.072 & 3.533 & $0.04^{*}$ & 1.229 & 0.307 \\
\hline \multicolumn{17}{|l|}{ Prades } \\
\hline Season & 0.001 & 0.981 & 19.143 & $0.000^{* * *}$ & 1.739 & 0.187 & 3.812 & $0.029^{*}$ & 2.744 & 0.074 & 1.602 & 0.212 & 5.367 & $0.001^{* *}$ & 4.449 & $0.002^{* *}$ \\
\hline Treat & 0.529 & 0.473 & 0.802 & 0.375 & 5.630 & $0.022^{*}$ & 8.468 & $0.005^{* *}$ & 2.450 & 0.124 & 4.162 & $0.047^{*}$ & 0.836 & 0.440 & 1.437 & 0.246 \\
\hline$S \times T$ & 0.196 & 0.661 & 0.100 & 0.905 & 0.496 & 0.612 & 0.384 & 0.683 & 1.049 & 0.358 & 0.716 & 0.494 & 0.421 & 0.659 & 0.313 & 0.733 \\
\hline
\end{tabular}

Categorical variables : site, season, treat (treatment; ctrl-drought) and $S \times T$ (season $\times$ treatment).

*Significant at $0.05 ;{ }^{* *} 0.005$; and ${ }^{* * *} 0.0005$ confidence interval.

$\mathrm{MB}$, microbial biomass; FB, fungal biomass; ANOvA, analysis of variance; BR, bacterial richness; $\mathrm{BH}$, bacterial Shannon-Weaver; FR, fungal richness; FH, fungal Shannon-Weaver; B PCA, bacterial principal component analyses; F PCA, fungal principal component analyses.

higher for the holm-oak forest than for Mediterranean shrubland soils (Fig. 2a). Results from a stepwise multiple regression further confirmed that soil fungal biomass was the best single factor explaining variance in SOM decomposition (semipartial correlation $=0.46$, $P<0.01$ ), outstripping fungal diversity, bacterial diversity, soil moisture, or soil organic C (semipartial correlations $0.22,0.16,0.15$ and 0.05 respectively) (Table 4).
Surprisingly, the response of soil $\mathrm{CO}_{2}$ effluxes to temperature was best explained by soil diversity (richness and/or the Shannon-Weaver diversity index) in fungal TRFs (Fig. 2b, Table 3). Again, values of $Q_{10}$ and values of fungal diversity were generally higher for the holm-oak forest than for Mediterranean shrubland soils (Fig. 2b). Results from a stepwise multiple regression analysis indicated that fungal TRF richness was the best single factor explaining 

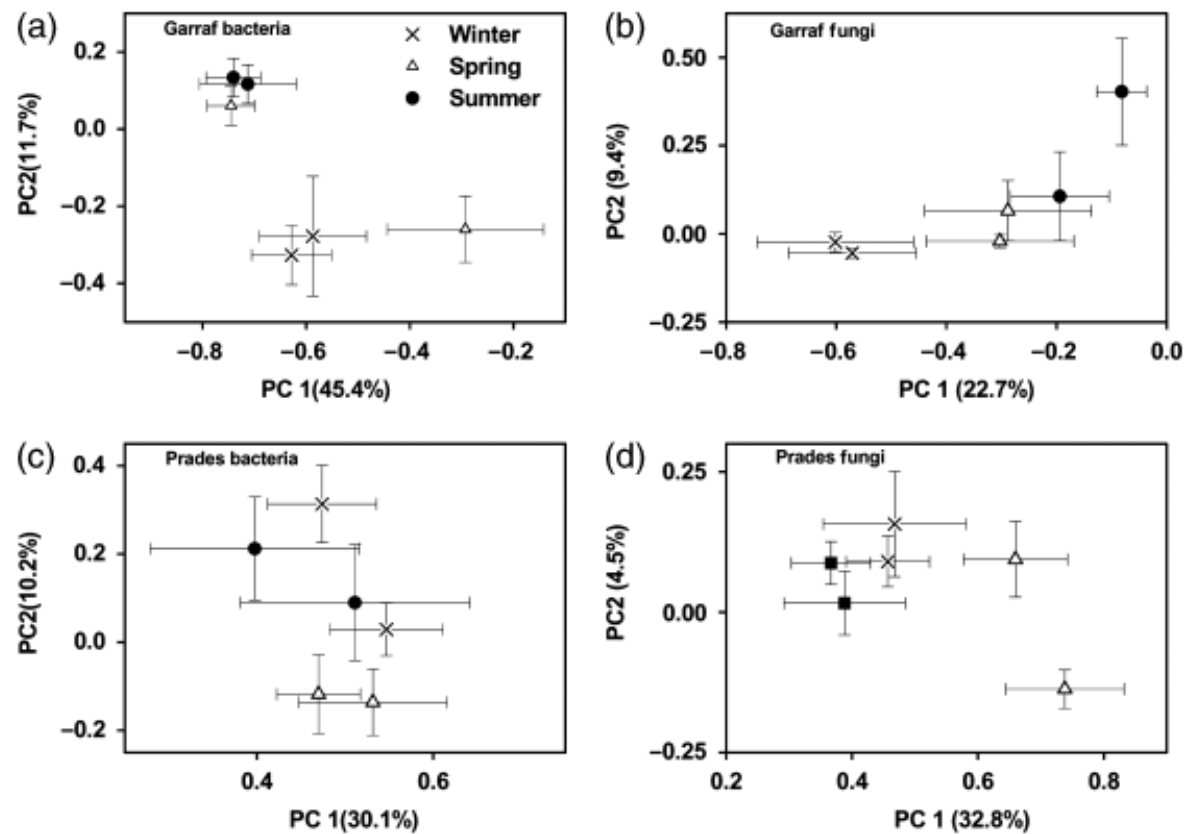

Fig. 1 Ordination plot of the first ( $X$-axis) and the second dimensions ( $Y$-axis) of principal coordinate (PCA) scores for the soil bacterial and fungal community at the two study sites. Symbols represent different seasons. Error bars represent the standard error of the mean. PCA, principal component analyses.
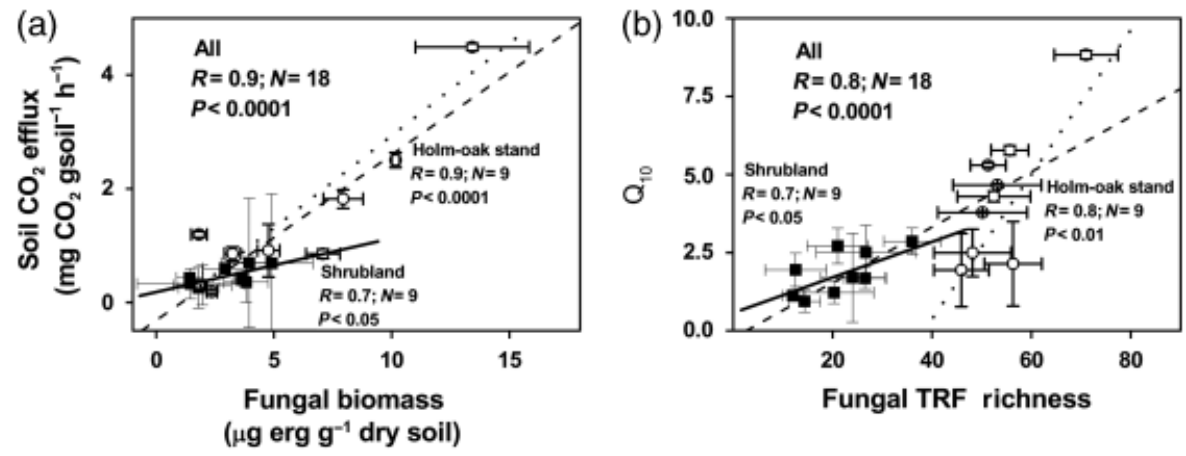

Fig. 2 Averaged values of soil $\mathrm{CO}_{2}$ efflux (grouped by season and treatment) (Fig. 1a) and $Q_{10}$ (temperature sensitivity coefficient) (Fig. $1 b$ ) as a function of the fungal biomass (left) and the fungal terminal restriction fragment (TRF) richness (right), respectively. Fungal biomass is given in ergosterol (erg) content units. Solid and dotted lines represent the linear fit of variables at each site (shrubland and forest, respectively) separately ( $N=9$ means \pm SE of three plots shown by bars). Dashed lines represent the linear fit when both sites were pooled together $(N=18$ means $\pm S E$ of three plots). The statistics of the linear fit (coefficient of correlation, $R$ and $P$ value of the fit) are provided for the entire data set (All), and for Garraf shrubland and Prades holm-oak forest separately.

variance in $Q_{10}$ (semipartial correlation $=0.52$, $P<0.01$ ), particularly in the holm-oak forest (see Table 2), surpassing soil moisture, fungal biomass, bacterial TRF richness, or soil organic C (semipartial correlations $-0.29,0.11,-0.05$ and -0.01 respectively) (Table 4). While the positive correlation was significant at both sites and within sites (Table 3), the effect of diversity on $Q_{10}$ was especially strong in soils from the holm-oak forest (red line in Fig. 2, Table 3), where both fungal biomass and fungal diversity were typically higher.

\section{Discussion}

Effect of site, season and treatment on the microbial community

Site, season and treatment exerted a strong influence over biomass, diversity and the structure of bacterial and fungal communities (Tables 1 and 2, Fig. 1). Site substantially influenced biomass (microbial and fungal), diversity of fungi and the bacterial and fungal community structure (Tables 1 and 2). Microbial and 
Table 3 Pearson's correlation coefficients of the individual linear correlations of SOM decomposition (SOM dec) and $Q_{10}$ with the independent explanatory variables studied

\begin{tabular}{|c|c|c|c|c|c|c|}
\hline & \multicolumn{2}{|l|}{ All data } & \multicolumn{2}{|c|}{ Garraf shrubland } & \multicolumn{2}{|c|}{ Prades forest } \\
\hline & SOM dec & $Q_{10}$ & SOM dec & $Q_{10}$ & SOM dec & $Q_{10}$ \\
\hline \multicolumn{7}{|l|}{ Soil moisture } \\
\hline Pearson correlation & 0.414 & -0.409 & 0.271 & -0.301 & 0.258 & -0.608 \\
\hline Significant (two-tailed) & 0.087 & 0.092 & 0.481 & 0.432 & 0.503 & 0.082 \\
\hline$N$ & 18 & 18 & 9 & 9 & 9 & 9 \\
\hline \multicolumn{7}{|l|}{ Fungal biomass } \\
\hline Pearson correlation & 0.802 & 0.265 & 0.697 & 0.567 & 0.902 & -0.22 \\
\hline Significant (two-tailed) & $0.001^{* *}$ & 0.287 & $0.037^{*}$ & 0.111 & $0.001^{* *}$ & 0.57 \\
\hline$N$ & 18 & 18 & 9 & 9 & 9 & 9 \\
\hline \multicolumn{7}{|l|}{ Bacteria richness } \\
\hline Pearson correlation & 0.193 & -0.184 & -0.127 & -0.14 & 0.582 & -0.22 \\
\hline Significant (two-tailed) & 0.443 & 0.465 & 0.745 & 0.72 & 0.1 & 0.57 \\
\hline$N$ & 18 & 18 & 9 & 9 & 9 & 9 \\
\hline \multicolumn{7}{|l|}{ Bacteria Shannon-Weaver } \\
\hline Pearson correlation & 0.171 & -0.183 & -0.246 & -0.197 & 0.753 & 0.151 \\
\hline Significant (two-tailed) & 0.498 & 0.467 & 0.524 & 0.611 & $0.019^{*}$ & 0.698 \\
\hline$N$ & 18 & 18 & 9 & 9 & 9 & 9 \\
\hline \multicolumn{7}{|l|}{ Fungal richness } \\
\hline Pearson correlation & 0.492 & 0.798 & 0.373 & 0.67 & -0.071 & 0.82 \\
\hline Significant (two-tailed) & $0.038^{*}$ & $0.0001^{* * *}$ & 0.323 & $0.048^{*}$ & 0.856 & $0.007^{* *}$ \\
\hline$N$ & 18 & 18 & 9 & 9 & 9 & 9 \\
\hline \multicolumn{7}{|l|}{ Fungi Shannon-Weaver } \\
\hline Pearson Correlation & 0.459 & 0.762 & 0.303 & 0.67 & 0.066 & 0.697 \\
\hline Significant (two-tailed) & 0.055 & $0.0001^{* * *}$ & 0.429 & $0.048^{*}$ & 0.865 & $0.037^{*}$ \\
\hline$N$ & 18 & 18 & 9 & 9 & 9 & 9 \\
\hline \multicolumn{7}{|l|}{ Microbial biomass } \\
\hline Pearson correlation & 0.273 & 0.179 & 0.409 & -0.19 & -0.432 & -0.069 \\
\hline Significant (two-tailed) & 0.416 & 0.598 & 0.494 & 0.76 & 0.392 & 0.896 \\
\hline$N$ & 11 & 11 & 5 & 5 & 6 & 6 \\
\hline \multicolumn{7}{|l|}{ Total organic C } \\
\hline Pearson correlation & 0.165 & 0.11 & 0.185 & 0.024 & 0.297 & 0.022 \\
\hline Significant (two-tailed) & 0.513 & 0.665 & 0.634 & 0.951 & 0.438 & 0.955 \\
\hline$N$ & 18 & 18 & 9 & 9 & 9 & 9 \\
\hline
\end{tabular}

The significant explanatory variables for SOM decomposition and $Q_{10}$ are highlighted in bold type.

*Significant at $0.05 ;{ }^{* *} 0.005$; and ${ }^{* * *} 0.0005$ confidence interval.

SOM, soil organic matter.

fungal biomasses, SOM decomposition rates and fungal diversity were all significantly higher in the holm-oak than in the Mediterranean shrubland (Tables 1 and 2). Indeed, the holm-oak forest holds more soil C (averaging 2.2\% and 3.5\% C in Garraf and Prades, respectively) and biomass (Ogaya \& Peñuelas, 2007; Peñuelas et al., 2007) compared with the Garraf shrubland. However the forest also emits more soil $\mathrm{CO}_{2}$ (Asensio et al., 2007, 2008) and shows higher soil enzymatic activity (Sardans et al., 2008; Sardans \& Peñuelas, 2010). Therefore our results coincide quite well with the differences in biological activity between sites observed in former studies. The low fungal diversity in Garraf might be interpreted as an effect of the harsh environmental conditions and low productivity of this site (Rajaniemi, 2003) with respect to Prades. On the other hand, our results indicate that bacterial diversity was not sensitive to site. It should be noted, however, that the values of bacterial diversity obtained in this study were at the very low end of those observed in soils with similar $\mathrm{pH}^{\prime} \mathrm{s}$ (Fierer \& Jackson, 2006), indicating that bacterial diversity might have been equally affected at both sites.

Fungal biomass was also strongly affected by seasonality at both sites (Tables 1 and 2) particularly because of the high fungal biomasses observed during winter (Table 1). This high fungal activity could be due to the combination of low plant-resource competition in win- 
ter and good abiotic conditions (high moisture and mild temperatures) typical of the Mediterranean winters. Indeed soils of these Mediterranean ecosystems maintain a high potential enzymatic activity during winter time (Sardans et al., 2008; Sardans \& Peñuelas, 2010) and the high SOM decomposition rates observed in winter in this study (Table 1) support this idea.

Season also affected the diversity of bacteria as well as bacterial and fungal community structure (Tables 1 and 2). Nevertheless, the observed seasonality of bacterial diversity was not necessarily positively correlated with moisture (Tables 1 and 2), which in Mediterranean ecosystems is generally the limiting factor on the seasonal scale (J. C. Yuste, S. Vicca, I. A. Janssens, M. Bahn, S. Luyssaert, B. Longdoz, D. D. Baldocchi, E. A. Davidson, J. Peñuelas, M. Reichstein, N. Arriga, J. M. Aubinet, N. Buchmann, A. Carrara, C. Gimeno, T. Gruenwald, B. F. Lobster, S. Ma, M. Mencuccini, L. Misson, L. Montagnani, F. Moyano, M. Pavelka, J. Pumpanen, Richardson, N. A. Rurh, M. Suleau, J. W. Tang, M. S. Torn, R. Vargas, G. Wohlfahrt \& W. Kutsch, unpublished results). Seasonality does, however, not only implies changes in climate but also in plant productivity and hence supply of resources to soils. The relationship between microbial diversity and productivity is rather complex (Waldrop \& Firestone, 2006a, b) because few species can withstand low resource levels. But as the resource level increases and more species meet their minimum resource requirements, other processes such as competitive exclusion (Rajaniemi, 2003) and/or topdown predatory interactions (Worm et al., 2002) may also lead to a reduction in diversity. Therefore the relationships between bacterial diversity and seasonality are quite complex and in our study no single environmental factor appeared to control the observed seasonal variations.

Results from the PCA analyses further demonstrated that season exerted a stronger effect over the structure of the microbial community than treatment. This can be seen by the position in the ordination plot in dimensions 1 and 2 of the PCA analyses (Fig. 1, Table 2). Unlike fungal diversity (Table 2), fungal community structure showed strong sensitivity to season at both sites (Fig. 1), indicating that the phylotypes associated to the TRF peaks changed seasonally without a general loss in diversity. Indeed, the microbial community can possess the metabolic and genetic capability of adapting to changing environmental conditions on short-time scales, e.g. seasonally (Lipson et al., 2002, 2009; Waldrop \& Firestone, 2006a,b; Schmidt et al., 2007; Williams, 2007). Our results therefore indicate that as the seasonal environmental conditions changed, the phylotype composition of the microbial communities could adapt accordingly without a general loss in diversity. 
Treatment, on the other hand, affected preferentially the bacterial more than the fungal community (Table 2). At both sites we observed a greater, though not significant, decline in microbial biomass, covering both fungal and bacterial biomasses, than in fungal biomass alone (Table 1). This suggests that drought probably affected the bacterial biomass more than the fungal. Furthermore, the 10 years drought resulted in a significant decline in bacterial diversity at both sites especially in holm-oak forest soils, while no effect on fungal diversity was observed (Table 1 and 2). Our results suggest that increasing drought conditions appear to favor a fungal-rich microbial community, as fungi were able to overcome better the disadvantages of drier conditions than bacteria. These results, therefore, raise the question as to whether future 'drier conditions,' as projected by models for the Mediterranean regions (Gibelin \& Deque, 2003) might eventually favor fungal dominated microbial communities. A shift to fungaldominated communities may have important consequences for soil nutrient cycling because it is believed that fungal-dominated communities sequester more $\mathrm{C}$ than bacterial-dominated communities (Martin \& Haider, 1979; Holland \& Coleman, 1987; Beare et al., 1997; Bailey et al., 2002; Six et al., 2006). In our study, longterm drought affected significantly $(0.05 \%$ conf. $T$-test $)$ soil organic C concentration in Garraf soils $(1.9 \pm 0.2 \%$ $\mathrm{C}$ content in treatment with respect to $2.5 \pm 0.3 \% \mathrm{C}$ in drought soils, at $10 \mathrm{~cm}$ depth), but did not affect soil organic C concentration in Prades soils (3.4\% C content at both soils, ctrl and treatment). Nonetheless soil organic $\mathrm{C}$ depends not only on the microbial community responsible for OM decomposition but also on the productivity (inputs) of the system, that were not measured in this study. Although no conclusive results could be drawn, the relation between the fungal community and the stabilization of SOM in Mediterranean ecosystems could be a key issue that requires further study.

\section{Drivers of SOM decomposition and $\mathrm{Q}_{10}$ variability}

We also report strong correlations between fungal biomass and SOM decomposition (Fig. 2a, Tables 3 and 4) and between fungal diversity and response to temperature $\left(Q_{10}\right)$ (Fig. $2 b$, Tables 3 and 4 ). This indicates that besides the observed capacity of the fungal community to resist both long-term- and seasonally induced environmental changes better than bacteria, the biomass and diversity of fungi played a central role in the decomposition of SOM. These results add to a growing number of studies that confirm the important and active role that the microbial community can play in soil $\mathrm{C}$ balance (Balser \& Firestone, 2005; Aerts, 2006; Waldrop \& Firestone, 2006a, b; Balser \& Wixon, 2009; Strickland et al.,
2009). This contrasts with the more classical vision of the microbial community having a passive role in the oxidation of SOM, as a result of a high degree of functional redundancy (Gitay et al., 1996).

Fungal biomass explained variability in SOM decomposition better than other variables such as TOC, microbial biomass or moisture. This result indicates that the decomposition of SOM in the two ecosystems studied was strongly bound to the presence of fungi. In contrast, recent studies on a subalpine conifer forest highlighted the role of bacteria over that of fungi in the seasonality of heterotrophic respiration (Lipson et al., 2009). However fungi are a key functional group within the soil microbial community that overall contributes substantially to the decomposition of SOM. Fungi dominate the production of a wide range of extracellular enzymes that break down complex high molecular organic matter, particularly lignocelluloses and humus (Peay et al., 2008). The microbial community therefore benefits greatly from the presence of fungi as important providers of assimilable (low molecular weight) substrate and nutrients to the whole microbial community (Beare et al., 1992). This together with the observed resistance of fungi to the relatively harsh environments of these Mediterranean ecosystems (Tables 1 and 2) suggests that the fungal community is playing a central role in the soil $\mathrm{C}$ balance of those ecosystems. It follows that our results indicate that the relative role of bacteria and fungi may vary according to the abiotic/biotic conditions of different ecosystems. While this is only speculative, future studies should be designed to understand the different roles of fungal and bacterial communities in SOM decomposition in different ecosystems.

In addition our results show that the response of SOM decomposition to temperature was highly correlated to the diversity of the fungal community, within and among sites (Fig. 2b). It is difficult to interpret the possible cause-effect relation between diversity and $Q_{10}$ because this is, to the best of our knowledge, the first time it has been shown. It is possible that the strong/ sudden changes in temperature $\left(40{ }^{\circ} \mathrm{C}\right.$ in $\left.48 \mathrm{~h}\right)$ favored more diverse fungal communities, because they are more likely to contain species able to respond to the fast warming of soils. Microbes can sense changing local conditions in seconds to minutes, and they come out of dormancy within minutes in response to a change (e.g. Fenchel, 2002). Therefore high $Q_{10}$ 's may represent the response of communities which are better adapted to temperature perturbations. This is in accordance with the 'insurance hypotheses,' which states that the more diverse a community is, the more likely it contains species able to tolerate and take advantage of a disturbance such as a temperature change (Chapin III et al., 
1992; Naeem \& Li, 1997). At least in the relatively harsh environments of Mediterranean ecosystems the redundancy of organisms within a functional group would be paramount for microbial communities to maintain their activity when faced with climatic disturbances.

Nonetheless we cannot conclude that the observed correlation between fungal diversity and $Q_{10}$ was necessarily causal. During the temperature cycles microbial communities may have undergone physiological and/or community changes beyond simple kinetics, e.g. temperature-induced stress, reflected in increases in the metabolic quotient at higher temperature (Pietikainen et al., 2005). However it is difficult to explain the mechanisms that make diverse communities more stressed than less diverse communities. Furthermore if high $Q_{10} \& a p s o ; s$ were related to stress, the $Q_{10}$ of drought stressed soils should have been higher than $Q_{10}$ for control soils, which was not the case (Table 1). Because ambient temperatures also change the optimal temperatures of soil microbial communities (BarcenasMoreno et al., 2009), the observed trend might be an acclimatization response by these microbial communities to the ambient temperatures at sampling date. This would explain the high responsiveness to temperature (high $Q_{10}$ 's) of the holm-oak soils collected during summer (Table 1). While such conclusions are not definitive as yet, our results suggest that the structure and diversity of the microbial community might not only affect its functionality, which has been previously observed in a number of studies, but it may also affect the responsiveness of soil ecosystems to climate.

\section{Concluding remarks}

Our results, therefore, support the three hypotheses raised in the study. Firstly, environmental changes associated to site and seasonality exerted a strong influence over the microbial structure, the diversity and the biomass of the microbial community. Fungal diversity was less sensitive to seasonal changes in moisture, temperature and plant activity than bacterial diversity. On the other hand, fungal communities showed the ability to dynamically adapt to changing environments without a loss of diversity. Secondly, fungi resisted the 10-year precipitation exclusion performed in water-limited Mediterranean ecosystems better than bacteria. The high resistance of the fungal community to changes raises the question as to whether future 'drier conditions' for the Mediterranean regions might favor fungal dominated microbial communities. Finally, our results further support our third hypothesis: The capacity of fungi to overcome disturbances played a pivotal role in shaping the microbial community and exerted a strong influence over the temporal and spatial variability of SOM decomposition, and hence over soil $\mathrm{C}$ dynamics. Fungal biomass and diversity, therefore, should be extensively and intensively explored in order to understand and correctly predict soil $\mathrm{CO}_{2}$ emissions from different types of ecosystems, especially in the frame of current human-driven alterations in the $\mathrm{C}$ cycle and the resulting climate change.

\section{Acknowledgements}

This research was supported by a Marie Curie Intra-European Fellowship (EIF) from the European Union for the project MICROCARB (FP6-2005-Mobility-5 \# 041409-MICROCARB). Additional partial funding was provided by the Spanish government projects CGL2006-04025, Consolider Ingenio Montes CSD2008-00040 and the Catalan government project SGR2009458. We are very grateful to Teresa Salvador Jofra and Evan Marks for technical support.

\section{References}

Aerts R (2006) The freezer defrosting: global warming and litter decomposition rates in cold biomes. Journal of Ecology, 94, 713-724.

Allison SD, Martiny JBH (2008) Resistance, resilience, and redundancy in microbial communities. Proceedings of the National Academy of Sciences of the United States of America, 105, 11512-11519.

Asensio D, Peñuelas J, Ogaya R, Llusià J (2007) Seasonal soil and leaf $\mathrm{CO}_{2}$ exchanges rates in a Mediterranean holm oak forest and their responses to drought conditions. Atmospheric Environment, 41, 2447-2455.

Asensio D, Peñuelas J, Prieto P, Estiarte M, Filella I, Llusià J (2008) Interannual and seasonal changes in the soil exchange rates of monoterpenes and other VOCs in a Mediterranean shrubland. European Journal of Soil Science, 59, 878-891.

Bailey VL, Smith JL, Bolton H (2002) Fungal-to-bacterial ratios in soils investigated for enhanced C sequestration. Soil Biology and Biochemistry, 34, 997-1007.

Balser TC, Firestone MK (2005) Linking microbial community composition and soil processes in a California annual grassland and mixed-conifer forest. Biogeochemistry, 73, 395-415.

Balser TC, Wixon DL (2009) Investigating biological control over soil carbon temperature sensitivity. Global Change Biology, 15, 2935-2949.

Barcenas-Moreno G, Gomez-Brandon M, Rousk J, Baath E (2009) Adaptation of soil microbial communities to temperature: comparison of fungi and bacteria in a laboratory experiment. Global Change Biology, 15, 2950-2957.

Bardgett RD, Hobbs PJ, Frostegård $\AA$ (1996) Changes in soil fungal: bacterial biomass ratios following reductions in the intensity of management of an upland grassland. Biology and Fertility of Soils, 22, 261-264.

Beare MH, Hu S, Coleman DC, Hendrix PF (1997) Influences of mycelial fungi on soil aggregation and organic matter storage in conventional and no-tillage soils. Applied Soil Ecology, 5, 211-219.

Beare MH, Parmelee RW, Hendrix PF, Cheng WX, Coleman DC, Crossley DA (1992) Microbial and faunal interactions and effects on litter nitrogen and decomposition in agroecosystems. Ecological Monographs, 62, 569-591.

Bond-Lamberty B, Wang CK, Gower ST (2004) A global relationship between the heterotrophic and autotrophic components of soil respiration? Global Change Biology, 10, 1756-1766.

Chapin III FS, Schulze ED, Mooney HA (1992) Biodiversity and ecosystem processes. Trends Ecol Evol, 7, 107-108.

Cox P (2001) Effects of fungal inocula on the decomposition of lignin and structural polysaccharides in Pinus sylvestris litter. Biology And Fertility Of Soils, 33, 246-251.

Cox PM, Betts RA, Jones CD, Spall SA, Totterdell IJ (2000) Acceleration of global warming due to carbon-cycle feedbacks in a coupled climate model. Nature, 408, 750-750.

Davidson EA, Janssens IA (2006) Temperature sensitivity of soil carbon decomposition and feedbacks to climate change. Nature, 440, 165-173.

Deacon JW (1985) Decomposition of filter-paper cellulose by thermophilic fungi acting singly, in combination, and in sequence. Transactions Of The British Mycological Society, 85, 663-669. 
De Boer W, Folman LB, Summerbell RC, Boddy L (2005) Living in a fungal world, Impact of fungi on soil bacterial niche development. FEMS, Microbiology Reviews, 29, 795-811.

Degens BP (1998) Decreases in microbial functional diversity do not result in corresponding changes in decomposition under different moisture conditions. Soil Biology and Biochemistry, 30, 1981-1988.

Ewbank G, Edwards D, Abbott GD (1996) Chemical characterization of lower Devonian vascular plants. Organic Geochemistry, 25, 461-473.

Fierer N, Jackson RB (2006) The diversity and biogeography of soil bacterial communities. Proceedings of the National Academy of Sciences of the United States of America, 103, 626-631.

Fenchel T. (2002) Microbial behavior in a heterogeneous world. Science, 296, 1068-1071. Friedlingstein P, Dufresne JL, Cox PM, Rayner P (2003) How positive is the feedback between climate change and the carbon cycle? Tellus Series B-Chemical and Physical Meteorology, 55, 692-700.

Gibelin AL, Deque M (2003) Anthropogenic climate change over the Mediterranean region simulated by a global variable resolution model. Climate Dynamics, 20, 327-339.

Gitay H, Wilson JB, Lee WG (1996) Species redundancy, a redundant concept? Journal of Ecology, 84, 121-124.

Grant WD, West AW (1986) Measurement of ergosterol, diaminopimelic acid and glucosamine in soil - evaluation as indicators of microbial biomass. Journal of Microbiological Methods, 6, 47-53.

Griffin DM (1985) A comparison of the roles of bacteria and fungi. In: Bacteria in Nature. Bacterial Activities in Perspective, Vol. 1 (eds Leadbetter ER, Poindexter JS), pp. 221-255. Academic Press, London.

Griffiths BS, Ritz K, Bardgett RD et al. (2000) Ecosystem response of pasture soil communities to fumigation-induced microbial diversity reductions: an examination of the biodiversity-ecosystem function relationship. Oikos, 90, 279-294.

Harris RF (1981) Effect of water potential on microbial growth and activity. In: Water Potential Relations in Soil Microbiology (eds Parr JF, Gardner WR, EllioMRT LF), pp. 23-95. ASA, Madison, WI.

Holland EA, Coleman DC (1987) Litter placement effects on microbial and organic matter dynamics in an agroecosystem. Ecology, 68, 425-433.

Hulot FD (2000) Functional diversity governs ecosystem response to nutrient enrichment. Nature, 405, 340-344.

IPCC (lntergovernamental Panel of Climate Change) (2007) Climate Change 2007: The Physical Science Basis: Summary for Policymakers. World Meteorological Organization, Geneva, Switzerland. Available at http://www.ipcc.ch/wgl (accessed 23 December 2009).

Jennings DH (1987) Translocation of solutes in fungi. Biological Reviews, 62, 215-243.

Kirschbaum MUF (2006) The temperature dependence of organic-matter decomposition - still a topic of debate. Soil Biology and Biochemistry, 38, 2510-2518.

Larcher W (2000) Temperature stress and survival ability of Mediterranean sclerophyllous plants. Plant Biosystems, 134, 279-295.

Lipson DA, Monson RK, Schmidt SK, Weintraub MN (2009) The trade-off between growth rate and yield in microbial communities and the consequences for undersnow soil respiration in a high elevation coniferous forest. Biogeochemistry, 95 23-35.

Lipson DA, Schadt CW, Schmidt SK (2002) Changes in soil microbial community structure and function in an alpine dry meadow following spring snow melt. Microbial Ecology, 43, 307-314.

Martin JP, Haider K (1979) Biodegradation of 14C-labeled model and cornstalk lignins, phenols, model phenolase humic polymers, and fungal melanins as influenced by a readily available carbon source and soil. Applied and Environmental Microbiology, 38, 283-289.

Meir P, Cox P, Grace J (2006) The influence of terrestrial ecosystems on climate. Trends in Ecology and Evolution, 21, 254-260.

Moorhead DL, Sinsabaugh RL (2006) A theoretical model of litter decay and microbial interaction. Ecological Monographs, 76, 151-174.

Naeem S, Li S (1997) Biodiversity enhances ecosystem reliability. Nature, 390, 507-509.

Ogaya R, Peñuelas J (2007) Tree growth, mortality, and above-ground biomass accumulation in a holm oak forest under a five-year experimental field drought. Plant Ecology, 189, 291-299.

Papendick RI, Campbell GS (1981) Theory and measurement of water potential. In: Water Potential Relations in Soil Microbiology. SSSA Special Publication No. 9 (ed. Parr JF), pp. 1-22. SSSA, Madison.
Peay KG, Kennedy PG, Bruns TD (2008) Fungal community ecology, a hybrid beast with a molecular master. Bioscience, 58, 799-810.

Peñuelas J, Prieto P, Beier C et al. (2007) Response of plant species richness and primary productivity in shrublands along a north-south gradient in Europe to seven years of experimental warming and drought, reductions in primary productivity in the heat and drought year of 2003. Global Change Biology, 13, 2563-2581.

Pietikainen J, Pettersson M, Baath E (2005) Comparison of temperature effects on soil respiration and bacterial and fungal growth rates. FEMS Microbiology Ecology, 52, 49-58.

Rajaniemi TK (2003) Explaining productivity-diversity relationships in plants. Oikos, 101, 449-457.

Rayner ADM (1994) Pattern-generating processes in fungal communities. In: Beyond the Biomass British Society of Soil Sciences (eds Ritz K, Dighton J, Giller KE), pp. 247-258. Wiley-Sayce, New York.

Robinson CH (1993) Nutrient and carbon-dioxide release by interacting species of straw-decomposing fungi. Plant and Soil, 151, 139-142.

Robinson JM (1996) Atmospheric bulk chemistry and evolutionary megasymbiosis. Chemosphere, 33, 1641-1653.

Sambrook J, Fritsch EF, Maniatis T (1989) Molecular Cloning, A Laboratory Manual. Sect 6.1-6.19, 2nd edn. Cold Spring Harbor Laboratory Press, Cold Spring Harbor, NY

Sardans J, Peñuelas J (2010) Soil enzyme activity in a Mediterranean forest after six years of drought. Soil Science Society of American Journal, 74, 838-851.

Sardans J, Peñuelas J, Estiarte M (2008) Changes in soil enzymes related to C and N cycle and in soil $\mathrm{C}$ and $\mathrm{N}$ content under prolonged warming and drought in a Mediterranean shrubland. Applied Soil Ecology, 39, 223-235.

Schröter D, Cramer W, Leemans R et al. (2005) Ecosystem service supply and vulnerability to global change in Europe. Science, 310, 1333-1337.

Schmidt SK, Costello EK, Nemergut DR et al. (2007) Biogeochemical consequences of rapid microbial turnover and seasonal succession in soil. Ecology, 88, 1379-1385.

Six J, Frey SD, Thiet RK, Batten KM (2006) Bacterial and fungal contributions to carbon sequestration in agroecosystems. Soil Science Society of America Journal, 70, 555-569.

Soil Survey Staff (1998) Soil Taxonomy: A Basis System of Soilclassification for Making and Interpreting Soil Surveys. US, Agricultural Handbook, Vol. 436. US Government Printing Office, Washington, DC.

Specht RL, Moll EJ, Pressinger F, Sommerville J (1983) Moisture regime and nutrient control of seasonal growth in Mediterranean ecosystems. In: Mediterranean-type Ecosystems. The Role of Nutrients. (eds Kruger FJ, Mitchell DT, Jarvis JUM), pp. 120-132. Springer, Berlin.

Strickland MS, Lauber C, Fierer N, Bradford MA (2009) Testing the functional significance of microbial community composition. Ecology, 90, 441-451.

Taylor TN, Osborne JM (1996) The importance of fungi in shaping the paleoecosystem. Review of Palaeobotany and Palynology, 90, 249-262.

Vance ED, Brookes PC, Jenkinson DS (1987) An extraction method for measuring soil microbial biomass-C. Soil Biology and Biochemistry, 19, 703-707.

Waldrop MP, Firestone MK (2006a) Seasonal dynamics of microbial community composition and function in oak canopy and open grassland soils. Microbial Ecology, 52, 470-479.

Waldrop MP, Firestone MK (2006b) Response of microbial community composition and function to soil climate change. Microbial Ecology, 52, 716-724

Wall DH (1999) Interactions underground - soil biodiversity, mutualism, and ecosystem processes. Bioscience, 49, 109-117.

Williams MA (2007) Response of microbial communities to water stress in irrigated and drought-prone tallgrass prairie soils. Soil Biology and Biochemistry, 39, 2750-2757.

Williams MA, Rice CW (2007) Seven years of enhanced water availability influences the physiological, structural, and functional attributes of a soil microbial community. Applied Soil Ecology, 35, 535-545.

Worm B, Lotze HK, Hillebrand H, Sommer U (2002) Consumer versus resource control of species diversity and ecosystem functioning. Nature, 417, 848-851.

Yuste JC, Baldocchi DD, Gershenson A et al. (2007) Microbial soil respiration and its dependency on carbon inputs, soil temperature and moisture. Global Change Biology, 13, 2018-2035.

Yuste JC, Ma S, Baldocchi DD (2010) Plant-soil interactions and acclimation to temperature of microbial-mediated soil respiration may affect predictions of soil $\mathrm{CO}_{2}$ efflux. Biogeochemistry, 98, 127-138. 